\title{
Measurement and Simulation of Mosfet Device Parameters
}

\author{
Ahmet TOPRAK \\ Department of Electric and Energy/Bozkır Vocational School/Selçuk \\ University/Konya/Turkey
}

\begin{abstract}
Knowing the current-voltage (I-V) characteristics of MOSFETs used as switching devices is very important in circuit designs where detailed specifications are needed. Therefore, preapplication simulation is very important. Simulation of power electronic devices can be done with MATLAB, PSpice and LTSpice software packages.

In this study we measured a commercial MOSFET devices and compared with the LTSpice and MATLAB/Simulink simulation. Two-channel power supply, which can be controlled by a PC or a GPIB, is required to measure the I-V characteristics of MOSFET devices. We measured the MOSFET with a Keithley 2634B Power Supply. The MOSFET measurements were limited to $\pm 20.2 \mathrm{~V}$ at $\pm 1.5 \mathrm{~A}$ maximum or $\pm 202 \mathrm{~V}$ at $\pm 100 \mathrm{~mA}$ maximum per channel by the power supply. It is found that good agreements observed between measurement and simulations in output and transfer characteristics.
\end{abstract}

Keywords: MOSFET, MATLAB/Simulink, LTSpice

\section{INTRODUCTION}

When designing and implementing a circuit, the measurement of a MOSFET's I-V characteristics become important. With a realistic SPICE model of the device, we can predict the risks of damage prior to application. Manufacturers provide datasheets of these devices with detail. However, the given data in datasheets is mostly on the extreme values rather than the average values. This is particularly important when a MOSFET is desired to operate at $0-5 \mathrm{~V}$ gate voltage provided by microprocessors. For this reason, we need to measure the currentvoltage characteristics of these devices in detail $[1,2]$.

\section{DEVICE CHARACTERISTICS}

MOSFET device parameters, such as threshold voltage $\left(\mathrm{V}_{\mathrm{th}}\right)$, current on/off ratio ( $\left.\mathrm{I}_{\mathrm{on} / \mathrm{off}}\right)$ and sub-threshold swing (SS), are usually inferred from the output and transfer characteristics. The drain current $\left(\mathrm{I}_{\mathrm{DS}}\right)$ is plotted versus the drain voltage $\left(\mathrm{V}_{\mathrm{DS}}\right)$ for various gate voltages $\left(\mathrm{V}_{\mathrm{GS}}\right)$ and is called the transfer characteristic. The drain current $\left(\mathrm{I}_{\mathrm{DS}}\right)$ is plotted versus the $\mathrm{V}_{\mathrm{GS}}$ for various $\mathrm{V}_{\mathrm{DS}}$ and is called transfer characteristic [3,4].

For small drain-source voltages, $\mathrm{V}_{\mathrm{DS}} \mathrm{Q}\left(\mathrm{V}_{\mathrm{GS}} \mathrm{Q \textrm {V } _ { \mathrm { th } }}\right)$, the MOSFET is in linear mode and IDs is described by: 
(1)

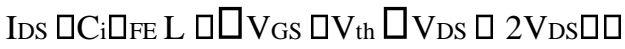

$\square$

- If $\square v_{D S} \Delta u V_{G S} \Delta V_{t h} \square$, the MOSFET is in saturation mode. IDs is independent of $\mathrm{V}_{\mathrm{DS}}$ and is described by:

$\begin{array}{llll}1 \mathrm{~W} & { }^{2} 2 & \mathrm{~L}\end{array}$

$\mathrm{I}_{\mathrm{DS}} \square \overline{\mathrm{C}}_{\mathrm{i}} \square_{\text {sat }} \square \mathrm{V}_{\mathrm{GS}} \square \mathrm{V}_{\text {th }} \square$

(Saturation region) (2)

where $\mathrm{W}$ is the channel width, $\mathrm{L}$ is the channel length, $\mathrm{C}_{\mathrm{i}}$ is the capacitance per unit area of the dielectric layer, $V_{G S}$ is the gate-source voltage, $V_{D S}$ is the drain-source voltage, $V_{\text {th }}$ is the threshold voltage, $\mu_{\mathrm{FE}}$ is the field effect mobility and $\mu_{\text {sat }}$ is the saturation mobility.

\section{MEASUREMENT RESULT}

"Power MOSFET devices, to measure their I-V characteristics under a PC's control, require a power supply with a minimum of two independently variable DC source channels which can be controlled by a PC via a serial, or a GPIB, or a USB interface" [5] or Ethernet. For benchtop use, Series 2600B SMU (Source Measure Unit) instruments feature built-in, Java-based test software that enables true plug \& play I-V characterization through any browser, on any computer, from anywhere in the world. Our experiments were conducted with a Keithley 2634B Dual Power Supply unit. The maximum voltage and current measurement ranges of our system are limited by the power supply. The MOSFET measurements were limited to $\pm 20.2 \mathrm{~V}$ at $\pm 1.5 \mathrm{~A}$ maximum or $\pm 202 \mathrm{~V}$ at $\pm 100 \mathrm{~mA}$ maximum per channel by the power supply. With other models of Keithley, the measurement capability can be increased up to $40 \mathrm{~V}$ at $100 \mathrm{~A}$ or $3 \mathrm{kV}$ at $20 \mathrm{~mA}$. Figure 1 shows Keithly 2634B power supply and MOSFET, which was IXTP3N120 MOSFET from IXYS Corporation. The gate and source terminals were connected to Channel A of the power supply and the drain and source terminals were connected to Chanel B of the power supply and also the negative terminals of the two channels were short-circuited [5].

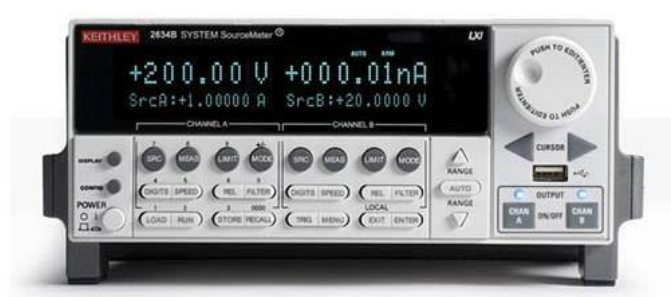

Figure 1. Keithly 2634B Power Supply

The output and transfer characteristics, presented in Figure 2, were obtained at gate voltage range of $5 \mathrm{~V}, 6 \mathrm{~V}, 7 \mathrm{~V}$ and $10 \mathrm{~V}$ from measurements with Keithley 2634B Semiconductor Characterization System. 

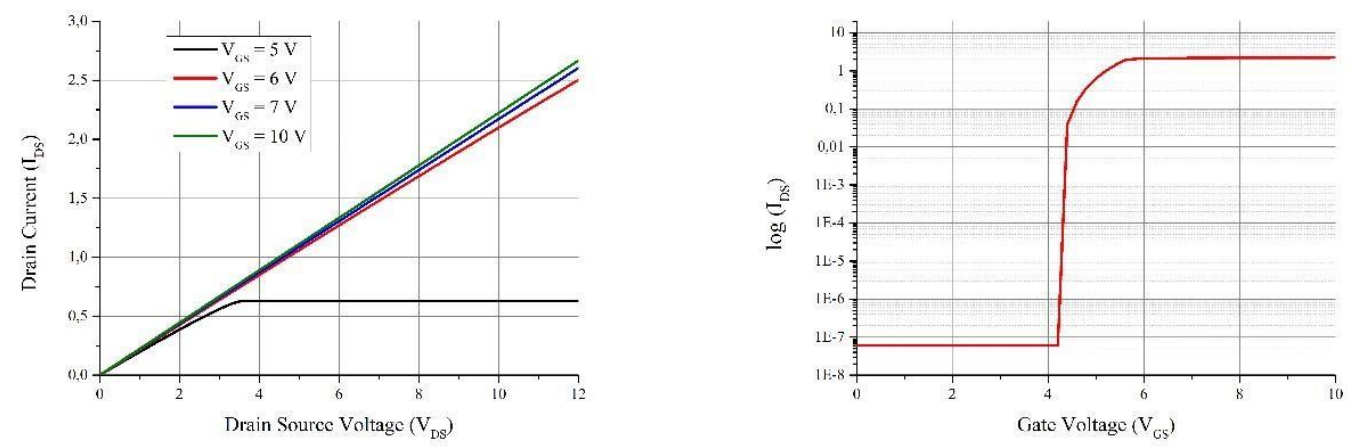

Figure 2. a) Output Characteristic and b) Transfer Characteristic

From the transfer characteristic, we determined the threshold voltage, an on/off ratio and a subthreshold swing of $4.2 \mathrm{~V}, 10^{7}$ and $0.033 \mathrm{~V} /$ decade, respectively.

\section{SIMULATION}

In this section, the MOSFET device was simulated with two different simulation programs, which were MATLAB/Simulink and LTSpice, and the I-V characteristics (output and transfer characteristics) were plotted. MOSFET parameters used in MATLAB/Simulink and LTSpice simulation, which were obtained from the producer, are summarized in table 1.

Table 1. MOSFET parameters

\begin{tabular}{|l|c|}
\hline L & $2,0000 \mathrm{E}-06$ \\
\hline W & $3,9000 \mathrm{E}+00$ \\
\hline KP & $1,0336 \mathrm{E}-06$ \\
\hline RS & $1,0000 \mathrm{E}-02$ \\
\hline RD & $4,4019 \mathrm{E}+00$ \\
\hline VTO & $4,2036 \mathrm{E}+00$ \\
\hline RDS & $9,6000 \mathrm{E}+07$ \\
\hline TOX & $2,0000 \mathrm{E}+06$ \\
\hline CGSO & $3,4138 \mathrm{E}-10$ \\
\hline CGDO & $8,9791 \mathrm{E}-12$ \\
\hline CBD & $1,7596 \mathrm{E}-09$ \\
\hline MJ & $8,5605 \mathrm{E}+04$ \\
\hline PB & $3,9050 \mathrm{E}+03$ \\
\hline RG & $1,0000 \mathrm{E}-02$ \\
\hline IS & $6,0436 \mathrm{E}-08$ \\
\hline N & $1,7204 \mathrm{E}+00$ \\
\hline RB & $1,0000 \mathrm{E}-09$ \\
\hline
\end{tabular}




\subsection{MATLAB Based Simulation Method}

MATLAB/Simulink model of MOSFET device is shown in Figure 3. The Level 1 SPICE NMOS block from the SimElectronics library was used to capture the DC performance of the MOSFET. The Level 1 model is the simplest way to represent the physical properties of a MOSFET [6]. Parameters, which are listed in table 1, used for MOSFET device simulation. The output and transfer characteristics obtained from simulation with MATLAB/Simulink are shown in figure 4.

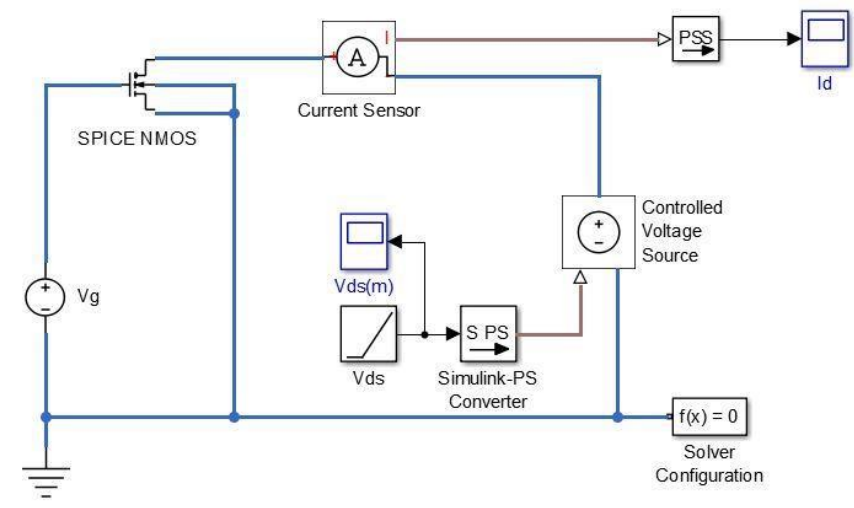

Figure 3. MATLAB Simulink Model of MOSFET
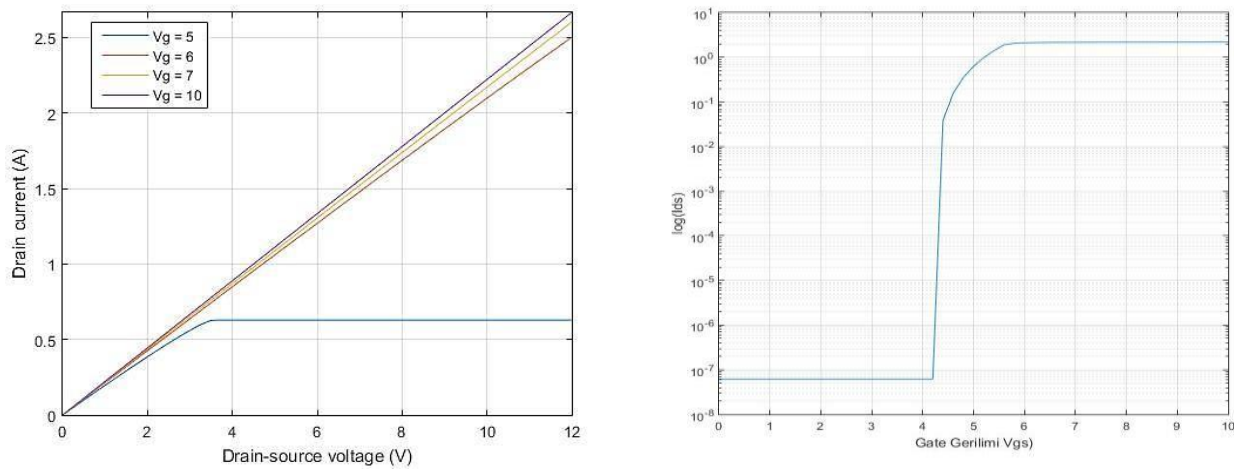

Figure 4. a) Output Characteristic and b) Transfer Characteristic

From the transfer characteristic, we determined the threshold voltage, an on/off ratio and a subthreshold swing of $4.2 \mathrm{~V}, 10^{7}$ and $0.035 \mathrm{~V} /$ decade, respectively.

\section{2. $\quad$ SPICE Based Simulation Method}

"SPICE is an acronym for Simulation Program with Integrated Circuit Emphasis and was inspired by the need to accurately model devices used in integrated circuit design. It has now become the standard computer program for electrical and electronic simulation" [7]. We used "LTSpice" program, which has developed by Linear Technology Corporation, was used to simulate for MOSFET device. Parameters listed in table 1 were used for MOSFET device simulation. The output and transfer characteristics, shown in figure 6, were obtained from simulation with LTSpice. 


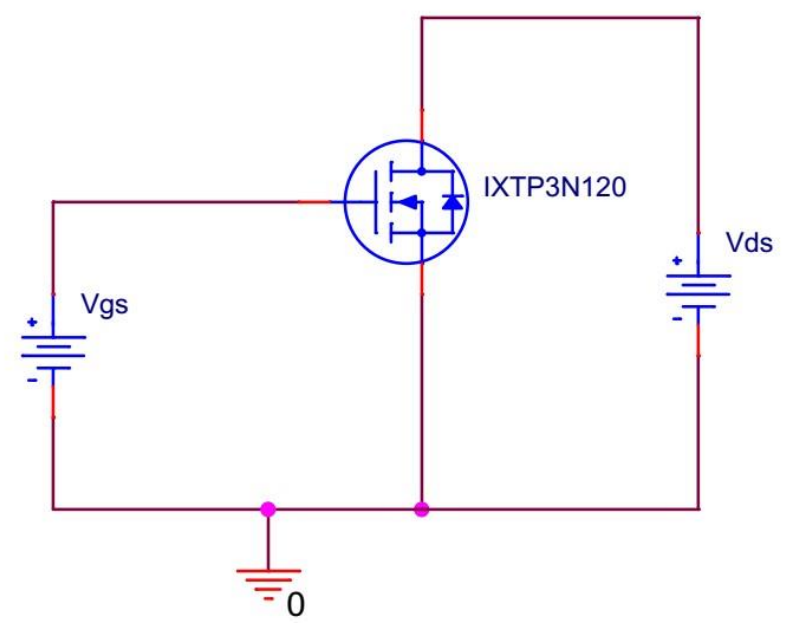

Figure 5. LTSpice Model of MOSFET
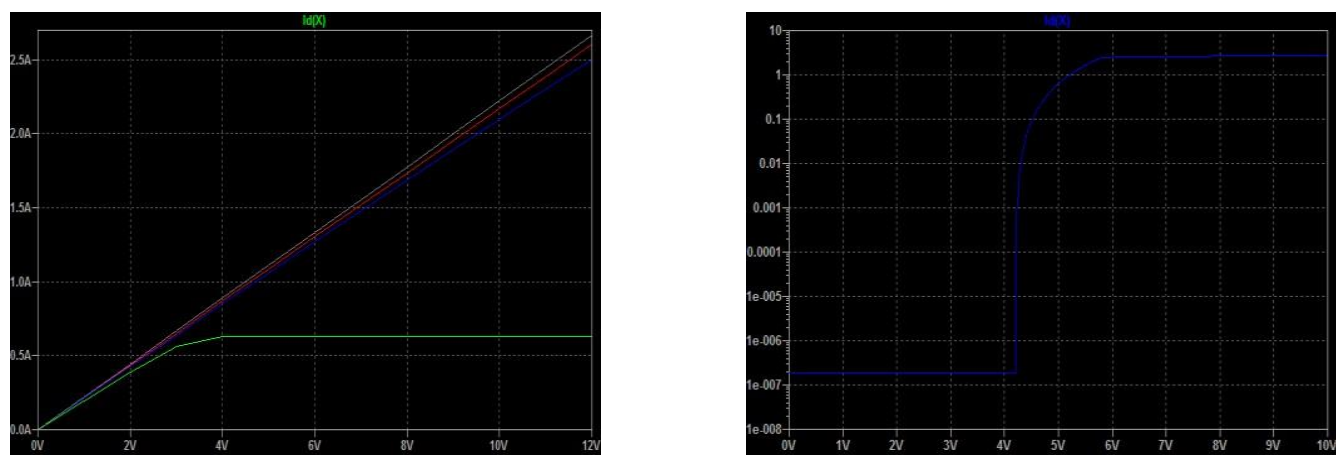

Figure 6. a) Output Characteristic and b) Transfer Characteristic

From the transfer characteristic, we determined the threshold voltage, an on/off ratio and a subthreshold swing of $4.25 \mathrm{~V}, 10^{6}$ and $0.030 \mathrm{~V} /$ decade, respectively.

\section{CONCLUSION}

The paper presents the output and transfer characteristics of MOSFET, which were obtained from measurement and simulation. In this study, we measured the MOSFET device and simulated by using MATLAB/Simulink and LTSpice. It has been seen that the output and transfer characteristics obtained from the measurement and Simulations are compatible with each other. Also the good agreement between the simulation results and datasheets can be observed in the paper.

\section{REFERENCES}

[1] A. Bonea, T. Hassinen, B. A. Ofrim, D. C. Bonfert, and P. Svasta, "Analytical Modeling of Contact Resistance in Organic Transistors," pp. 2-5. 
[2] U. Farok et al., "Electrical characterization and source-drain voltage dependent mobility of p-channel organic field-effect transistors using MATLAB simulation," Proceedings - 1st International Conference on Artificial Intelligence, Modelling and Simulation, AIMS 2013, pp. 459-461, 2014.

[3] T. Kamiya, K. Nomura, and H. Hosono, "Present status of amorphous In-Ga-Zn-O thin-film transistors," Science and Technology of Advanced Materials, vol. 11, p. 044305, 2010.

[4] B. Chandar Shekar, J. Lee, S.-w. Rhee, and B. C. Shekar, "Organic thin film transistors: Materials, processes and devices," Korean Journal of Chemical Engineering, vol. 21, pp. 267-285, 2004.

[5] S. Portland, "Automated Measurement of Power MOSFET Device Characteristics Using USB Interfaced Power Supplies Automated Measurement of Power MOSFET Device Characteristics Using USB Interfaced Power Supplies," 2016.

[6] G. Kampitsis, M. Antivachis, S. Kokosis, S. Papathanassiou, and S. Manias, "An accurate Matlab/Simulink based SiC MOSFET model for power converter applications," Conference Proceedings - IEEE Applied Power Electronics Conference and Exposition - APEC, vol. 2015-May, pp. 1058-1064, 2015.

[7] Y. YANG, L. ZHANG, and H. ZHENG, "Research on Modeling and Simulation in Virtual Experiment System," Proceedings of 2009 4th International Conference on Computer Science \& Education, pp. 1090-1094, 2009.

die 